\title{
Inhibition of TRPC6 Signal Pathway Alleviates Podocyte Injury Induced by TGF- $\beta 1$
}

\author{
Haiting Huang Xu Lin Yanwu You Chunrong Tang Xiangjun Gu Meiying Huang \\ Youling Qin Junhua Tan Feifan Huang
}

Department of Nephrology, The Affiliated Hospital of Youjiang Medical University for Nationalities, Baise, China

\author{
Key Words \\ Podocytes $•$ TGF- $\beta 1 \cdot$ TRPC6 $•$ Nephrin $•$ Desmin $•$ Caspase 9
}

\begin{abstract}
Background/Aims: Transforming growth factor beta 1 (TGF- $\beta 1$ ) plays a critical role in the pathogenesis of glomerulosclerosis. The purpose of this study was to examine the effects of inhibition of transient receptor potential cation channel C6 (TRPC6) on podocyte injury induced by TGF- $\beta 1$ via nephrin and desmin mechanisms. Methods: A rat model of nephropathy was first induced by intravenous injections of adriamycin to determine TRPC6 signal pathway engaged in glomerulosclerosis in vivo. Conditionally immortalized podocytes were cultured in vitro and they were divided into four groups: control; TGF- $\beta 1$ treatment; TGF- $\beta 1$ with TRPC6 knockdown and TGF- $\beta 1$ without TRPC6 knockdown. Real time RT-PCR and Western blot analysis were employed to determine the mRNA and protein of expression of nephrin, desmin and caspase-9, respectively. Flow cytometry was used to examine the apoptotic rate of podocytes and DAPI fluorescent staining was used to determine apoptotic morphology. Results: In vivo experiment, adriamycin significantly upregulated the protein expression of TGF- $\beta 1$, TRPC6, desmin and caspase-9, and decreased nephrin. Consistent with the latter results, in vitro experiment mRNA and protein expression of desmin and caspase- 9 was increased in cultured TGF- $\beta 1$-treated podocytes, whereas nephrin was declined as compared with the control group. Importantly, TRPC6 knockdown significantly attenuated the upregulated desmin and caspase-9, and alleviated impairment of nephrin induced by TGF- $\beta 1$. Moreover, typical morphologic features were presented in apoptotic podocytes. The number of apoptotic podocytes was increased after exposure to TGF- $\beta 1$ and this was alleviated after TRPC6 knockdown. TRPC6 knockdown also decreased an apoptosis rate of TGF- $\beta 1$-treated podocytes. Note that negative TRPC6 transfection control failed to alter an increase of the apoptosis rate in TGF- $\beta 1$-treated podocytes. Conclusions: TGF- $\beta 1$ induced by glomerulosclerosis impairs the protein expression of nephrin and amplifies the protein expression of desmin and caspase -9 via TRPC 6 signal pathway. Inhibition of TRPC 6 alleviates these changes in podocytes-treated with TGF- $\beta 1$ and attenuated apoptosis of podocytes.
\end{abstract}


Our data suggest that TRPC6 signal plays an important role in mediating TGF- $\beta 1$-induced podocyte injury via nephrin, desmin and caspase-9. Results of the current study also indicate that blocking TRPC6 signal pathway has a protective effect on podocyte injury. Targeting one or more of these signaling molecules may present new opportunities for treatment and management of podocyte injury observed in glomerulosclerosis.

\section{Introduction}

Transforming growth factor beta 1 (TGF- $\beta 1$ ) is a polypeptide member of the transforming growth factor beta superfamily of cytokines $[1,2]$. It is a secreted protein that performs many cellular functions including the control of cell growth, proliferation and differentiation; and dysregulation of TGF- $\beta$ activation and signaling results in cell apoptosis. [3-5]. Notably, TGF- $\beta 1$ is one of important cytokines in renal tissues in contribution to the pathogenesis of glomerulosclerosis [6]. Overexpression of TGF- $\beta 1$ has been revealed in kidney diseases of human and animal models and TGF- $\beta 1$ produced in glomerulus plays a role in regulating multiple pathophysiological functions in the process of the diseases [6-8]. For instance, TGF- $\beta 1$ stimulates expansion of extracellular matrix (ECM) and exacerbates podocyte injury including changes of cell morphology, detachment from glomerular basement membrane and apoptosis $[9,10]$. Prior studies have further demonstrated a number of intracellular signal pathways [i.e., mitogen-activated protein kinase (MAPK), extracellular signal-regulated kinase (ERK), phosphatidyl inositol- 3-kinase (PI3K) and nuclear factor- $\kappa \mathrm{B}$ (NF- $\kappa \mathrm{B}$ ) etc.] in involvement of podocyte injury induced by TGF- $\beta 1$ [11-13].

Transient receptor potential cation ion channel C6 (TRPC6) is a multiple transmembrane protein and mediates the release of cytosolic compartmentalized calcium [14, 15]. It is activated by mechanical stimuli such as membrane stretch and/or by diacylglycerol via phospholipase C mechanisms [16]. The Src kinase Fyn also increases TRPC6 channel conductivity [17]. It should be noted that TRPC6 is localized in podocyte and mutated in patients who have a subset of autosomal dominant focal segmental glomerulosclerosis (FSGS) $[15,18,19]$. Prior studies have also shown that mutated TRPC6 increases the cytosolic calcium signals $[18,20]$. Nonetheless, the precise mechanisms by which TRPC6 mediates glomerular podocyte injuries induced by TGF- $\beta 1$ remain to be determined. Thus, the purpose of this study was to determine engagement of nephrin and desmin in TRPC6 modulating podocyte injury induced by TGF- $\beta 1$. First, we induced nephropathy (an analogue of human FSGS) in rats by intravenous injections of adriamycin (ADR) [21] and further examined the protein expression of TGF- $\beta 1$, TRPC6, nephrin, desmin and caspase-9 in glomerulosclerosis in vivo. Second, we performed in vitro experiments to determine the effects of TRPC6 knockdown on TGF- $\beta 1$-induced podocyte apoptosis. We hypothesized that ADR upregulates TGF- $\beta 1$ and TRPC6 and thereby impairing the protein expression of nephrin and exaggerating expression of desmin and caspase -9. We further hypothesized that nephrin and desmin mechanisms are involved in apoptosis of podocyte caused by heightened TGF- $\beta 1$. We also hypothesized that knockdown of TRPC6 attenuates podocyte apoptosis induced by TGF- $\beta 1$ and alleviates the abnormalities in nephrin and desmin.

\section{Materials and Methods}

\section{Animals}

All experimental procedures were in accordance with the guidelines of the International Association for the Study of Pain and were approved by the Animal Research Committee of Youjiang Medical University for Nationalities. Male Sprague-Dawley rats weighing 200-250 g were used in this study. A rat model of nephropathy was induced by intravenous injections of ADR (4 mg/kg at the first week and $2 \mathrm{mg} / \mathrm{kg}$ at the fourth week) after the right kidney was extirpated as described previously [22]. Age- and body weight- 


\section{Cellular Physiology Cell Physiol Biochem 2017;41:163-172 \begin{tabular}{c|l|l} 
DOI: 10.1159/000455985 & (0) 2017 The Author(s). Published by S. Karger AG, Basel \\
www.karger.com/cpb
\end{tabular} \\ Huang et al.: TRPC6 Signaling and Podocyte Injury}

matched rats with sham-operation and saline injection were used as controls. Urine samples were collected before the surgery and at the end of each week. Then, urinary protein concentrations were determined by colorimetric assay (Bio-Rad) using bovine serum albumin (BSA) as the standard. Proteinuria was confirmed by urinary protein concentrations in samples. At the end of the sixth week rats were sacrificed and the kidney was removed for the Western blot analysis to determine the protein expression of TGF- $\beta 1$, TRPC6, nephrin, desmin and caspase-9.

\section{Podocyte culture and treatment}

Conditionally immortalized mouse podocyte cells were maintained at $33^{\circ} \mathrm{C}$ for proliferation in RPMI 1640 containing 10\% fetal bovine serum (Gibco) and 10U/ml of recombinant mouse $\gamma$-interferon (Invitrogen). They were then moved to $37^{\circ} \mathrm{C}$ for differentiation and cultured without $\gamma$-interferon. When they grew to about $80 \%$ confluence, podocytes were treated with $6 \mathrm{ng} / \mathrm{ml}$ of TGF- $\beta 1$ (Invitrogen) in serumfree medium and incubated with the PGPU6/GFP/Neo-TRPC6-mus-581 and PGPU6/GFP/Neo-NC according to the manufacture's protocol. Then, they were moved to $37^{\circ} \mathrm{C}$ and treated with $6 \mathrm{ng} / \mathrm{ml}$ of TGF- $\beta 1$ for 48 hours. Thus, the cultured podocytes were divided as control; TGF- $\beta 1$-treatment; TGF- $\beta 1$-treatment with PGPU6/GFP/Neo-TRPC6-mus-581 and TGF-B1-treatment with PGPU6/GFP/Neo-NC.

\section{Real-time PCR}

RT-PCR was performed using the TaqmanW Universal PCR Master Mix (Applied Biosys.). This mix contains AmpliTaq GoldW DNA Polymerase, AmpEraseW UNG, ROX passive reference, buffer and dNTPs, as well as gene-specific primers for the mRNA amplification of the following genes: nephrin, desmin and caspase -9. In addition, $18 \mathrm{~s}$ rRNA (TaqmanW PDAR) was used as an endogenous control to correct for variations in the samples. RT-PCR was performed in duplicate in 96-well plates containing $2 \mu \mathrm{L}$ of cDNA. The thermal conditions of the cycles were $50^{\circ} \mathrm{C}$ for 2 minutes, $60^{\circ} \mathrm{C}$ for 30 minutes, and $95^{\circ} \mathrm{C}$ for 5 minutes and this was followed by 40 cycles at $94^{\circ} \mathrm{C}$ for 20 seconds and $62^{\circ} \mathrm{C}$ for 60 seconds. The data were collected in the ABI PRISM SDS 7000 thermal cycler. Relative quantification of target gene expression was performed using the $2^{-\Delta \Delta \mathrm{Ct}}$ comparative method and the threshold cycle value was defined by the point at which there was a statistically significant detectable increase in fluorescence.

\section{Western blot}

Total protein in tissue and cells was extracted by homogenizing sample in ice-cold radioimmunoprecipitation assay buffer with protease inhibitor cocktail kit (Roche). The lysates were centrifuged and the supernatants were collected for measurements of protein concentrations using a bicinchoninic acid assay reagent kit. Fifty microgram of total protein was loaded to run $7.5 \%$ or $10 \%$ sodium dodecyl sulfate-polyacrylamide gel electrophoresis (SDS-PAGE), and the protein was transferred to nitrocellulose membranes (GE Healthcare Biosci). Then, the membranes were incubated for 30 minutes in 5\% low-fat milk prepared with Tris-buffered saline containing $0.05 \%$ Tween- 20 (TTBS). Subsequently, the membranes were incubated with primary antibodies as the rabbit anti-TGF- $\beta 1$, anti-TRPC6, anti-nephrin, anti-desmin and anti-caspase-9 (1:200-1:500, obtained from Neuromics and Abcam Co). After being fully washed, the membrane was incubated with horseradish peroxidase-linked anti-rabbit secondary antibody (1:250) and visualized for immunoreactivity. The membrane was also processed to detect $\beta$-actin or GAPDH for equal loading. The bands recognized by the primary antibody were visualized and the optical densities of protein bands were analyzed using the ImageJ software.

\section{Determination of apoptosis in cultured podocytes}

Annexin V-FITC Apoptosis Detection Kit (BD Biosciences) was applied to evaluate podocyte injury. Briefly, podocytes were harvested and washed twice with pre-cold phosphate-buffered saline (PBS). $1 \mathrm{x}$ $10^{6}$ cells were re-suspended in $1 \mu \mathrm{g} / \mathrm{ml}$ FITC-Annexin $\mathrm{V}$ for $30 \mathrm{~min}$ at $4^{\circ} \mathrm{C}$ followed by adding $5 \mu \mathrm{l}$ of 50 $\mu \mathrm{g} / \mathrm{ml}$ propidium iodide immediately prior to detection with flow cytometry (FACScan). Cells that stained positive for FITC Annexin $V$ and negative for propidium iodide were considered as undergoing apoptosis. Cells were characterized as viable, necrotic, early apoptotic or late apoptotic according to standard staining characteristics. The apoptosis rate was measured as the fraction of cells in early and late apoptosis. The measurement was repeated 3 times for each group and the mean value was obtained by averaging these data to indicate apoptosis rate. 


\section{Cellular Physiology Cell Physiol Biochem 2017;41:163-172 \begin{tabular}{ll|l} 
and Biochemistry Published onlIne: January 18, 2017 & $\begin{array}{l}\text { (C) } 2017 \text { The Author(s). Published by S. Karger AG, Basel } \\
\text { www.karger.com/cpb }\end{array}$
\end{tabular} \\ Huang et al.: TRPC6 Signaling and Podocyte Injury}

In addition, DAPI fluorescent staining was also used to assess apoptosis of podocytes. In this approach, podocytes were cultured and treated for 72 hours and then $10 \mu \mathrm{g} / \mathrm{ml}$ of DAPI in PBS was added at $37^{\circ} \mathrm{C}$ for $15 \mathrm{~min}$. DAPI-positive cells were observed using a fluorescence microscope and images were taken.

\section{Statistical analysis}

All data were analyzed using a two-way repeated-measures analysis of variance. Values were presented as means \pm standard error of mean (SEM). For all analyses, differences were considered significant at $P<$ 0.05. All statistical analyses were performed by using SPSS for Windows version 17.0 (SPSS, USA).

\section{Results}

In vivo experiments using a rat model of ADR nephropathy (ADRN)

In order to study the role of TRPC6 in the pathophysiological processes of ADRN, we first examined the protein expressions of TGF- $\beta 1$, TRPC6, nephrin, desmin and caspase-9 in situ renal tissues of the ADRN rat model. Figure 1(a) shows that the levels of urinary protein began to significantly increase 2 weeks after ADR injection and reached to a higher level at the sixth week. Then, the protein levels of TGF- $\beta 1$, TRPC6, nephrin, desmin and caspase- 9 were determined in control rats and ADRN rats with 6 weeks of ADR injection. Figure 1(b) shows that TGF- $\beta 1$, TRPC6, desmin and caspase- 9 were upregulated in ADRN rats $(P<0.05$ $v s$. control rats for all the proteins) whereas nephrin was decreased in ADRN rats $(P<0.05$ $v s$. control rats) as compared with control animals.

\section{Effectiveness in vitro experiments}

As demonstrated in Fig. 2(a), we first observed that the cultured podocyte appeared in a typical shape and a specific marker nephrin was contained in the cultured podocyte used in our experiments. Also, nephrin was identified by using the PCR method.

Figure 2(b) shows that expression of GFP on podocytes was increased 24 and 48 hours following transfection and it appeared slightly greater in 48 hours post-transfection than that in 24 hours post-transfection. In addition, Fig. 2(c) shows that downregulation of protein expression of TRPC6 was observed in podocytes in which PGPU6/GFP/Neo-TRPC6-mus-581 was transfected as compared with the control group and negative transfection group $(P<$ $0.05)$.

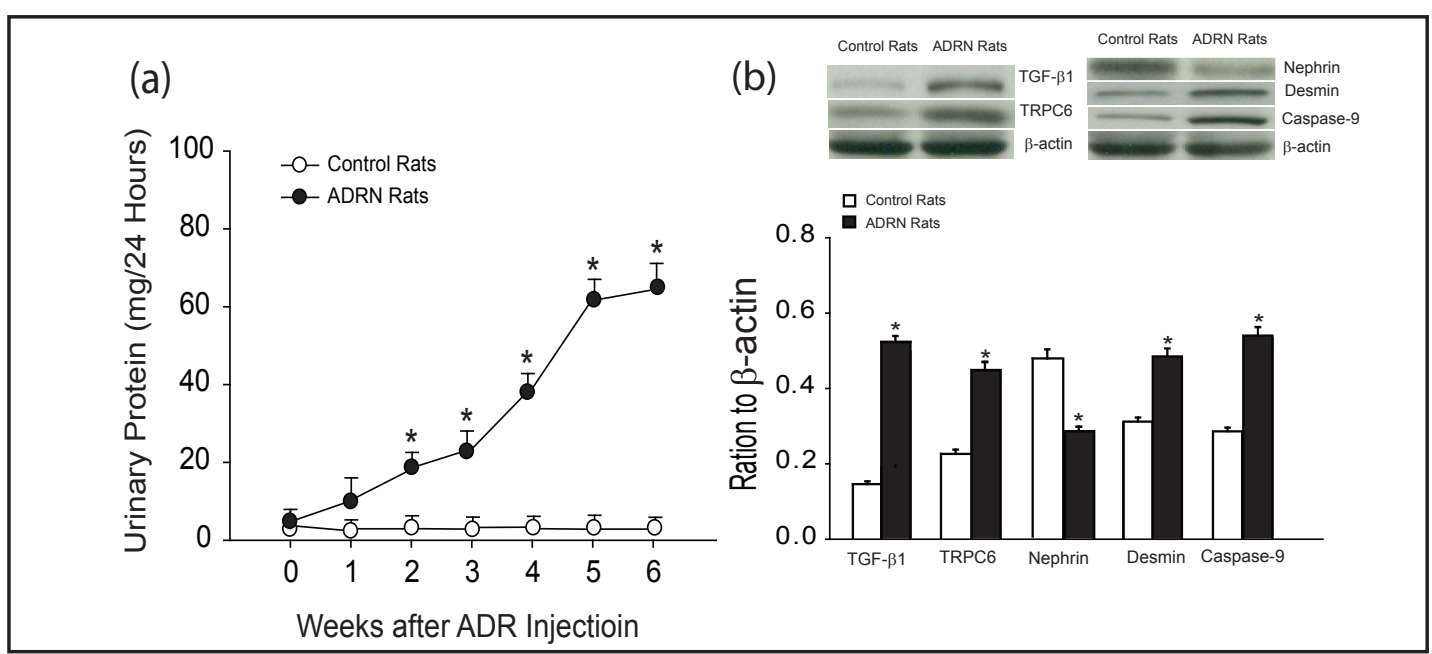

Fig. 1. (a) Effects of intravenous injection of ADR on urinary protein. The levels of urinary protein began to increase 2 weeks after ADR injection and reached to a high level at the sixth week. ${ }^{*} \mathrm{P}<0.05$ vs. control rats. The number of animals = 10 in control and 12 in ADR injection. (b) Protein expression of TGF- $\beta 1$, TRPC6, nephrin, desmin and caspase- 9 in the renal tissues. The top panels are typical bands and the bottom panels are averaged data. ${ }^{*} \mathrm{P}<0.05$ vs. control rats. 


\section{Cellular Physiology Cell Physiol Biochem 2017;41:163-172 \begin{tabular}{ll|l} 
DOI: 10.1159/000455985 & $\begin{array}{l}\text { O 2017 The Author(s). Published by S. Karger AG, Basel } \\
\text { www.karger.com/cpb }\end{array}$
\end{tabular}

Fig. 2. (a) The typical shape of cultured podocytes (\#1); a specific marker nephrin was contained in the cultured podocyte (\#2); and nephrin was identified in the cultured podocyte by the PCR band (\#3). Product size of the nephrin bands: 372 bp. (b) slightly greater expression of GFP on podocytes appears in 48 hours post-transfection (\#3) vs. 24 hours post-transfection (\#2) and negative transfection control (\#4). (c) Typical bands and averaged data showing downregulation of protein expression of

(a)
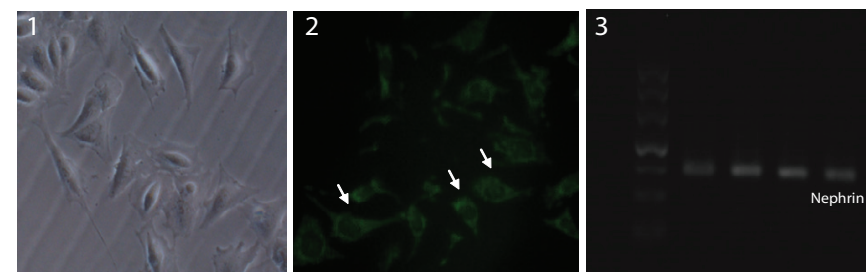

(b)
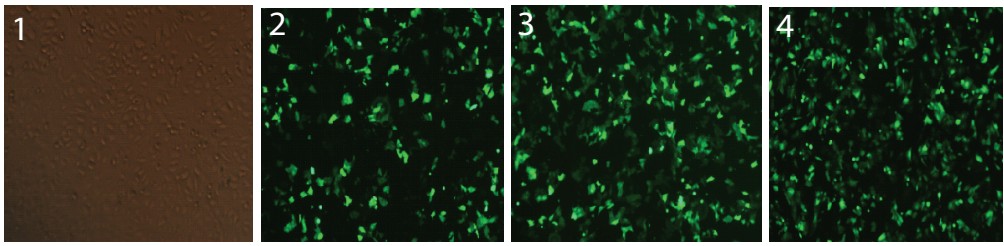

(c)

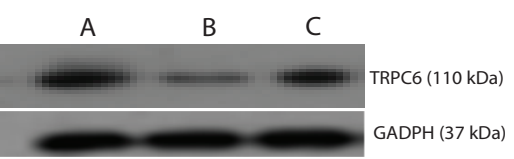

A: Control

B: PGPU6/GFP/Neo-TRPC6-mus-581

C: PGPU6/GFP/Neo-NC

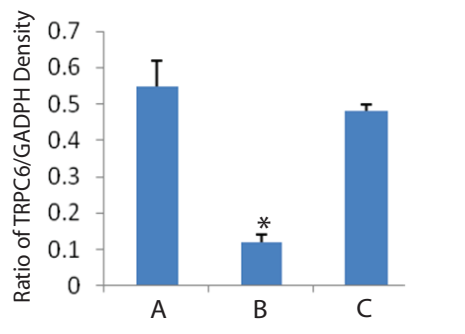

TRPC6 observed in podocytes with transfection of PGPU6/GFP/Neo-TRPC6-mus-581. * P $<0.05$ vs. control group and negative transfection group.

Fig. 3. (a) The expression of mRNA of desmin and caspase- 9 was increased in cultured TGF- $\beta 1$-treated podocytes, whereas mRNA of nephrin was decreased. TRPC6 knockdown significantly restored these changes. ${ }^{*} \mathrm{P}<0.05$ vs. $\beta 1$-treated podocytes without TRPC6 knockdown and $\beta 1$-treated podocytes with negative control. (b) Averaged data and typical bands showing the protein levels of desmin and caspase-9 expression were

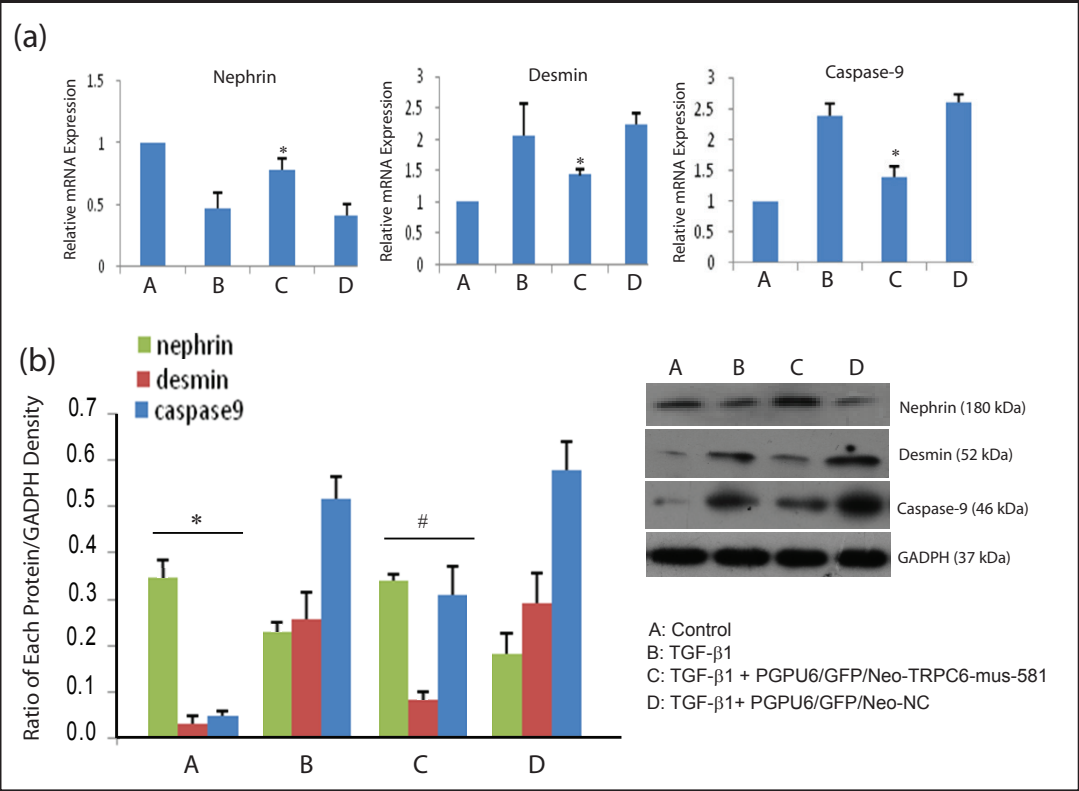
increased in cultured TGF- $\beta 1$-treated podocytes and nephrin was decreased. As TRPC6 was knocked down these changes were blunted. $* \mathrm{P}<0.05$ vs. $\beta 1$-treated podocytes without TRPC6 knockdown and $\beta 1$-treated podocytes with negative control. \# P $<0.05$ vs. $\beta 1$-treated podocytes without TRPC6 knockdown and $\beta 1$-treated podocytes with negative control.

Effects of TRPC6 knockdown on expression of nephrin, desmin and caspase-9

Figure 3 shows that as compared with the control group, mRNA and protein expression of desmin and caspase-9 was increased in cultured TGF- $\beta 1$-treated podocytes $(P<0.05)$, 


\section{Cellular Physiology Cell Physiol Biochem 2017;41:163-172 and Biochemistry Published 10,159/000455985 $20 \begin{aligned} & \text { O } 2017 \text { The Author(s). Published by S. Karger AG, Basel } \\ & \text { www.karger.com/cpb }\end{aligned}$

Fig. 4. (a \&b) TRPC6 knockdown decreased the apoptosis rate of TGF- $\beta 1$-treated podocytes compared with the rate without knockdown and negative control. * $\mathrm{P}$ $<0.05$ vs. control group; and \# $\mathrm{P}<0.05$ vs. TGF- $\beta 1$ treatment and TRPC6 negative control. Note that negative transfection control failed to alter an increase of apoptosis rate in TGF- $\beta 1$-treated podocytes. (c) Morphologic features of nucleus are presented in apoptotic podocytes (indicated by arrows on the right panel) vs. normal podocytes (indicated by arrows heads on the left panel). (d) The number of apoptotic podocytes was increased after exposure to

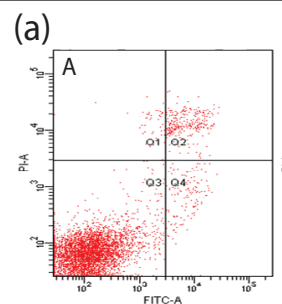

(b)
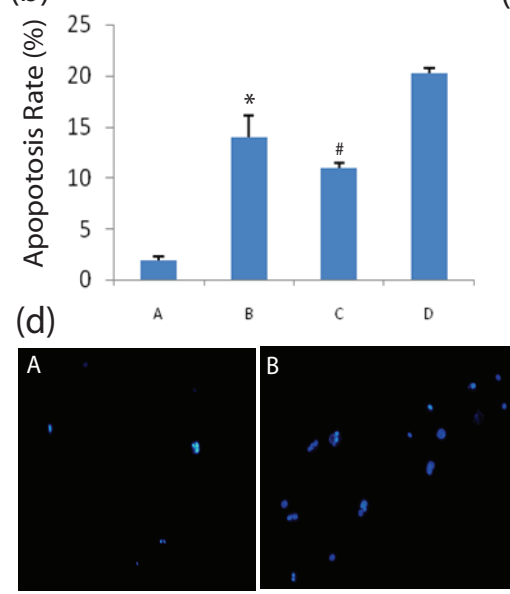

(c)
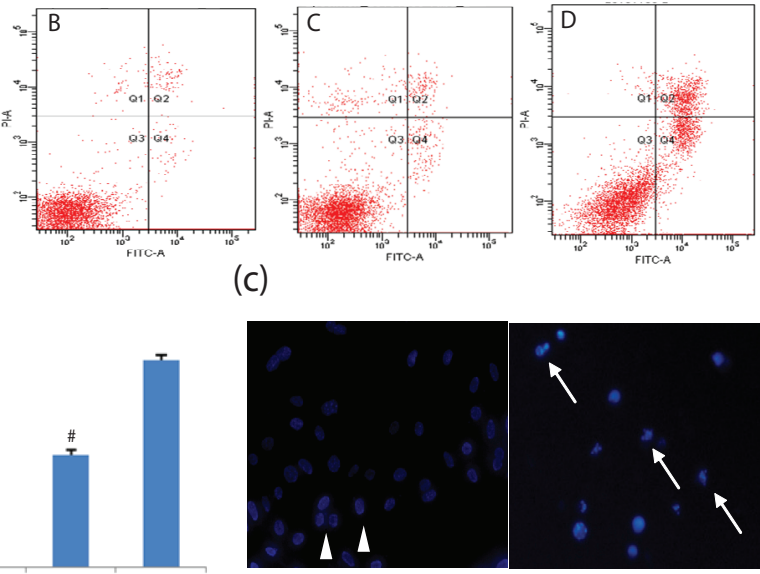

A: Contro

B: TGF- $\beta 1$

C: TGF- $\beta 1+$ PGPU6/GFP/Neo-TRPC6-mus-581

D: TGF- $\beta 1+$ PGPU6/GFP/Neo-NC

TGF- $\beta 1$ and this was attenuated after TRPC6 knockdown.

whereas mRNA and protein expression of nephrin was decreased $(P<0.05)$. In addition, TRPC6 knockdown significantly attenuated amplifications in desmin and caspase- 9 as well as a reduction in nephrin induced by 48 hours of TGF- $\beta 1$ treatment.

\section{Effects of TRPC6 knockdown on apoptosis of podocyte}

Figure 4 (a \& b) illustrate that TRPC6 knockdown decreased the apoptosis rate of TGF$\beta 1$-treated podocytes $(10 \pm 1 \%$ after TRPC6 knockdown vs. $14 \pm 2 \%$ without knockdown, $P$ $<0.05)$. Note that negative transfection control failed to alter an increase of apoptosis rate in TGF- $\beta 1$-treated podocytes. Moreover, Figure 4 (c \& d) illustrate that typical morphologic features were presented in apoptotic podocytes. This figure also shows that the number of apoptotic podocytes was increased after exposure to TGF- $\beta 1$ for 48 hours and this was attenuated after TRPC6 knockdown.

\section{Discussion}

ADR-induced nephropathy model has been considered as an analogue of human FSGS [21]. Prior studies suggest that TGF- $\beta 1 /$ Smad signaling activity plays a key role in the accumulation of ECM in ADRN [23]. In the present study using the same rat model, our results demonstrated that the protein expression of TGF- $\beta 1$, TRPC6, desmin and caspase- 9 are upregulated, whereas nephrin is decreased in ADRN rats. Consistently, we observed the same changes of desmin, caspase- 9 and nephrin in the cultured podocytes transfected with TGF- $\beta 1$. Considering that there are limitations for application of TRPC6 antagonist in vivo experiment and its specificity, we performed a series of in vitro experiments in order to determine the role played by TRPC6 in mediating TGF- $\beta 1$-induced podocyte injury. Our data showed that TRPC6 knockdown significantly alleviates impaired nephrin and attenuates 
amplifications in desmin and caspase- 9 observed in podocytes treated with TGF- $\beta 1$. Moreover, TRPC6 knockdown decreases an apoptosis rate of TGF- $\beta 1$-treated podocytes. Overall, our data suggest that molecular mediators such as desmin, caspase- 9 and nephrin are engaged in the role of TRPC6 signal in mediating podocyte injury induced by TGF- $\beta 1$.

In general, podocytes are the target of injury in chronic glomerular diseases. In these diseases, TGF- $\beta 1$ is secreted by mesangial cells and stored in ECM as latent complexes, and then transported to podocyte surface [24]. On podocytes, TGF- $\beta 1$ binds to its receptor and activate its downstream signaling pathways including Smad, MAPK, ERK and PI3K to modulate the expression of its target genes $[7,11,13]$. TGF- $\beta 1$ protein increases in these podocytes with the cellular lesions of FSGS $[7,8]$. It has been reported that TGF- $\beta 1$ reduces podocyte adhesion through $\alpha 3 \beta 1$ integrin downregulation and thus induces podocyte apoptosis [25].

In addition, podocytes undergo apoptosis at early stages in the course of progressive glomerulosclerosis in TGF- $\beta 1$ transgenic mice $[26,27]$. A prior study has demonstrated that local production of TGF- $\beta 1$ leads to the progression of podocyte damage [11]. In the cultured murine podocytes, it was also reported that TGF- $\beta 1$ induces podocyte apoptosis [28]. Interestingly, TRPC6 is induced in TGF- $\beta 1$-treated podocyte, implying that TRPC6 is likely involved in TGF- $\beta 1$-induced podocyte injury. In podocytes, it has been reported that the cytosolic free Ca2+ level is strongly regulated by TRPC6, which can be activated by the exogenous application of diacylglycerol. The enhanced cytosolic $\mathrm{Ca} 2+$ activates the $\mathrm{Ca} 2+$ dependent phosphatase calcineurin linked to the induction of apoptosis $[19,29]$. Therefore, TGF- $\beta 1$ is likely to affect TRPC6 channel activity in podocyte. Our present study found that TRPC6 knockdown attenuates the apoptosis rate in TGF- $\beta 1$-treated podocyte, which also is linked to impaired nephrin and upregulated desmin and caspase-9. These data suggest that these molecular protein mediators are necessary in involvement of TRPC6 signal engaged in podocyte damage induced by TGF- $\beta$.

Nephrin is a transmembrane protein that is a structural component of the slit diaphragm and necessary for the proper functioning of the renal filtration barrier [30-32]. The renal filtration barrier consists of fenestrated endothelial cells, the glomerular basement membrane, and the podocytes of epithelial cells [30-32]. They are present on the tips of the podocytes and maintain the normal relationship between the basement membrane and the podocytes of the epithelial cells. Nephrin regulates a number of pathways in the podocyte, suppresses cell death and apparently forms a complex with podocin [30]. Thus, depletion of nephrin and podocin is associated with degradation of the foot process [30]. A defect in the gene for nephrin, NPHS1, is associated with congenital nephrotic syndrome of the Finnish type and causes massive amounts of protein to be leaked into the urine or proteinuria [33]. Nephrin has also been used as a biomarker for kidney diseases [34]. Many factors inducing podocyte injury increase the levels of nephrin and direct evidence further shows that nephrin is very important in improving podocyte apoptosis of nephropathy including ADRN [35-38]. In our present study, we found that nephrin is impaired in ADRN rats and TGF- $\beta 1$ treated cultured podocytes. Inhibition of TRPC6 signal can restore the expression levels of its protein, indicating the crucial role played by TRPC6 in mediating podocyte injury induced by TGF- $\beta 1$ observed in ADRN.

Desmin is a type III intermediate filament that integrates the sarcolemma, $\mathrm{Z}$ disk and nuclear membrane in sarcomeresand regulates sarcomere architecture [39]. In adult muscle, desmin forms a scaffold around the Z-disk of the sarcomere and connects the Z-disk to the subsarcolemmal cytoskeleton [40]. It links to the myofibrils laterally by connecting the Z-disks [39]. Through its connection to the sarcomere, desmin connects the contractile apparatus to the cell nucleus, mitochondria, and post-synaptic areas of motor endplates [39]. These connections maintain the structural and mechanical integrity of the cell during contraction while they also help in force transmission and longitudinal load bearing [40,41]. Upregulated desmin expression is a defense mechanism in maintaining normal sarcomere alignment amidst disease pathogenesis [42]. There is evidence that desmin also connects the sarcomere to the ECM through desmosomes which is likely important in signaling between

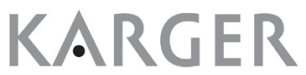




\section{Cellular Physiology Cell Physiol Biochem 2017;41:163-172

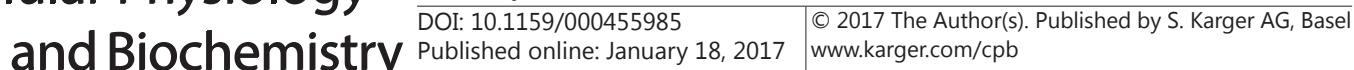 \\ Huang et al.: TRPC6 Signaling and Podocyte Injury}

the ECM and the sarcomere in regulating tissue contraction and movement [41]. Of note, prior studies suggest that desmin is a sensitive marker of podocyte injury [43]. Also, desmin mRNA and protein are increased in cultured mouse podocytes and in vivo study it has been reported that desmin is increased in damaged mouse podocytes by insults of numerous kidney disorders, suggesting that desmin is involved in podocyte injury [44, 45]. Moreover, recovering protein levels of desmin expression play a protective role in regulating injured podocytes [46-48]. Consistent with this notion, in the current study we found that desmin is exaggerated in ADRN rats and TGF- $\beta 1$-treated cultured podocytes and inhibition of TRPC6 alleviates exacerbated expression of desmin.

\section{Conclusions}

In ADRN, TGF- $\beta 1$, TRPC6 and caspase-9 are upregulated and this is likely to lead to apoptosis of podocyte. Also, this process impairs the protein expression of nephrin and amplifies expression of desmin. Knockdown of TRPC6 alleviates these changes in podocytes. The data suggest that TRPC6 plays an important role in mediating podocyte injury induced by TGF- $\beta 1$ and nephrin and desimin are necessary to be engaged in the role of TRPC6. Results of the current study also indicate that inhibition of TRPC6 signal pathways has a protective effect on podocyte injury. Targeting one or more of these signaling molecules may present new opportunities for treatment and management of podocyte injury observed in glomerulosclerosis.

\section{Acknowledgments}

This study was supported by The Natural Science Foundation of Guangxi (No.2014GXNSFAA118269).

\section{Disclosure Statement}

None.

\section{References}

1 Ghadami M, Makita Y, Yoshida K, Nishimura G, Fukushima Y, Wakui K, Ikegawa S, Yamada K, Kondo S, Niikawa N, Tomita H: Genetic mapping of the Camurati-Engelmann disease locus to chromosome 19q13.1-q13.3. Am J Hum Genet 2000;66:143-147.

-2 Vaughn SP, Broussard S, Hall CR, Scott A, Blanton SH, Milunsky JM, Hecht JT: Confirmation of the Mapping of the Camurati-Englemann Locus to 19q13.2 and Refinement to a 3.2-cM Region. Genomics 2000;66:119121.

- 3 Letterio JJ, Roberts AB: Regulation of immune responses by TGF- $\beta$. Ann Rev Immunol 1998;16:137-161.

-4 Oh SP, Seki T, Goss KA, Imamura T, Yi Y, Donahoe PK, Li L, Miyazono K, ten Dijke P, Kim S, Li E: Activin receptor-like kinase 1 modulates transforming growth factor- $\beta 1$ signaling in the regulation of angiogenesis. PNAS 2000;97:2626-2631.

5 Wahl SM, Wen J, Moutsopoulos N: TGF- $\beta$ : a mobile purveyor of immune privilege. Immunol Rev 2006;213:213-227.

6 Lee HS, Song CY: Effects of TGF-beta on podocyte growth and disease progression in proliferative podocytopathies. Kidney Blood Press Res 2010;33:24-29.

7 Kim TS, Kim JY, Hong HK, Lee HS: mRNA expression of glomerular basement membrane proteins and TGFbeta1 in human membranous nephropathy. J Pathol 1999;189:425-430. 


\section{Cellular Physiology Cell Physiol Biochem 2017;41:163-172

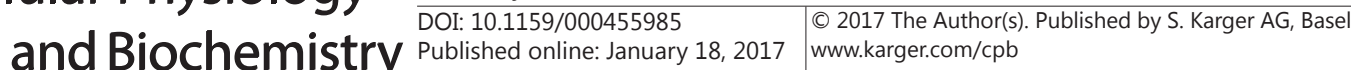 \\ Huang et al.: TRPC6 Signaling and Podocyte Injury}

8 Patek CE, Fleming S, Miles CG, Bellamy CO, Ladomery M, Spraggon L, Mullins J, Hastie ND, Hooper ML: Murine Denys-Drash syndrome: evidence of podocyte de-differentiation and systemic mediation of glomerulosclerosis. Hum Mol Genet 2003;12:2379-2394.

-9 Schnaper HW, Jandeska S, Runyan CE, Hubchak SC, Basu RK, Curley JF, Smith RD, Hayashida T: TGF-beta signal transduction in chronic kidney disease. Front Biosci (Landmark Ed) 2009;14:2448-2465.

10 Wynn TA: Cellular and molecular mechanisms of fibrosis. J Pathol 2008;214:199-210.

11 Massague J, Blain SW, Lo RS: TGFbeta signaling in growth control, cancer, and heritable disorders. Cell 2000;103:295-309.

-12 Sanz AB, Sanchez-Nino MD, Ramos AM, Moreno JA, Santamaria B, Ruiz-Ortega M, Egido J, Ortiz A: NFkappaB in renal inflammation. J Am Soc Nephrol 2010;21:1254-1262.

13 Schiffer M, Mundel P, Shaw AS, Bottinger EP: A novel role for the adaptor molecule CD2-associated protein in transforming growth factor-beta-induced apoptosis. J Biol Chem 2004;279:37004-37012.

14 Clapham DE: Calcium signaling. Cell 2007;131:1047-1058.

15 Mukerji N, Damodaran TV, Winn MP: TRPC6 and FSGS: the latest TRP channelopathy. Biochim Biophys Acta 2007;1772:859-868.

16 Spassova MA, Hewavitharana T, Xu W, Soboloff J, Gill DL: A common mechanism underlies stretch activation and receptor activation of TRPC6 channels. Proc Natl Acad Sci USA 2006;103:16586-16591.

17 Hisatsune C, Kuroda Y, Nakamura K, Inoue T, Nakamura T, Michikawa T, Mizutani A, Mikoshiba K: Regulation of TRPC6 channel activity by tyrosine phosphorylation. J Biol Chem 2004;279:18887-18894.

18 Reiser J, Polu KR, Moller CC, Kenlan P, Altintas MM, Wei C, Faul C, Herbert S, Villegas I, Avila-Casado C, McGee M, Sugimoto H, Brown D, Kalluri R, Mundel P, Smith PL, Clapham DE, Pollak MR: TRPC6 is a glomerular slit diaphragm-associated channel required for normal renal function. Nat Genet 2005;37:739744.

19 Winn MP, Conlon PJ, Lynn KL, Farrington MK, Creazzo T, Hawkins AF, Daskalakis N, Kwan SY, Ebersviller S, Burchette JL, Pericak-Vance MA, Howell DN, Vance JM, Rosenberg PB: A mutation in the TRPC6 cation channel causes familial focal segmental glomerulosclerosis. Science 2005;308:1801-1804.

20 Schlondorff J, Del Camino D, Carrasquillo R, Lacey V, Pollak MR: TRPC6 mutations associated with focal segmental glomerulosclerosis cause constitutive activation of NFAT-dependent transcription. Am J Physiol Cell Physiol 2009;296:C558-569.

21 Lee VW, Harris DC: Adriamycin nephropathy: A model of focal segmental glomerulosclerosis. Nephrology 2011;16:30-38.

22 Wan YG, Che XY, Sun W, Huang YR, Meng XJ, Chen HL, Shi XM, Tu Y, Wu W, Liu YL: Low-dose of multiglycoside of Tripterygium wilfordii Hook. a natural regulator of TGF-beta1/Smad signaling activity improves adriamycin-induced glomerulosclerosis in vivo. J Ethnopharmacol 2014;151:1079-1089.

23 Li J, Campanale NV, Liang RJ, Deane JA, Bertram JF, Ricardo SD: Inhibition of p38 mitogen-activated protein kinase and transforming growth factor-beta1/Smad signaling pathways modulates the development of fibrosis in adriamycin-induced nephropathy. Am J Pathol 2006;169:1527-1540.

24 Lee HS, Song CY: Differential role of mesangial cells and podocytes in TGF-beta-induced mesangial matrix synthesis in chronic glomerular disease. Histol Histopathol 2009;24:901-908.

25 Dessapt C, Baradez MO, Hayward A, Dei Cas A, Thomas SM, Viberti G, Gnudi L: Mechanical forces and TGFbeta1 reduce podocyte adhesion through alpha3beta1 integrin downregulation. Nephrol Dial Transplant 2009;24:2645-2655.

-26 Kopp JB, Factor VM, Mozes M, Nagy P, Sanderson N, Bottinger EP, Klotman PE, Thorgeirsson SS: Transgenic mice with increased plasma levels of TGF-beta 1 develop progressive renal disease. Lab Invest 1996;74:991-1003.

27 Sanderson N, Factor V, Nagy P, Kopp J, Kondaiah P, Wakefield L, Roberts AB, Sporn MB, Thorgeirsson SS: Hepatic expression of mature transforming growth factor beta 1 in transgenic mice results in multiple tissue lesions. Proc Natl Acad Sci USA 1995;92:2572-2576.

28 Schiffer M, Bitzer M, Roberts IS, Kopp JB, ten Dijke P, Mundel P, Bottinger EP: Apoptosis in podocytes induced by TGF-beta and Smad7. J Clin Invest 2001;108:807-816.

29 Goel M, Sinkins WG, Zuo CD, Estacion M, Schilling WP: Identification and localization of TRPC channels in the rat kidney. Am J Physiol Renal Physiol 2006;290:F1241-1252.

-30 Huber TB, Kottgen M, Schilling B, Walz G, Benzing T: Interaction with podocin facilitates nephrin signaling. J Biol Chem 2001;276:41543-41546. 


\section{Cellular Physiology Cell Physiol Biochem 2017;41:163-172

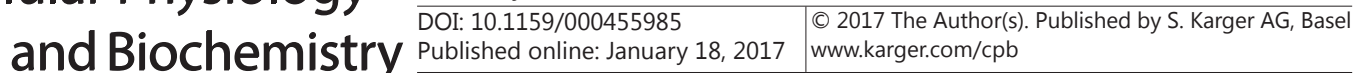 \\ Huang et al.: TRPC6 Signaling and Podocyte Injury}

31 Lehtonen S, Lehtonen E, Kudlicka K, Holthöfer H, Farquhar MG: Nephrin Forms a Complex with Adherens Junction Proteins and CASK in Podocytes and in Madin-Darby Canine Kidney Cells Expressing Nephrin. Am J Pathol 2004;165:923-936.

32 Yuan H, Takeuchi E, Salant DJ: Podocyte slit-diaphragm protein nephrin is linked to the actin cytoskeleton. Am J Physiol Renal Physiol 2002;282:F585-591.

-33 Wagner N, Morrison H, Pagnotta S, Michiels J-F, Schwab Y, Tryggvason K, Schedl A, Wagner K-D: The podocyte protein nephrin is required for cardiac vessel formation. Hum Mol Genet 2011;20:2182-2194.

-34 Perez-Hernandez J, Olivares MD, Forner MJ, Chaves FJ, Cortes R, Redon J: Urinary dedifferentiated podocytes as a non-invasive biomarker of lupus nephritis. Nephrol Dial Transplant 2016;31:780-789.

35 Jeong KH, Asanuma K, Lydia A, Takagi M, Asao R, Kodama F, Asanuma E, Tomino Y: Combination therapy with telmisartan and oxacalcitriol suppresses the progression of murine adriamycin nephropathy. Nephron 2015;129:143-154.

-36 Li X, Chuang PY, D'Agati VD, Dai Y, Yacoub R, Fu J, Xu J, Taku O, Premsrirut PK, Holzman LB, He JC: Nephrin Preserves Podocyte Viability and Glomerular Structure and Function in Adult Kidneys. J Am Soc Nephrol 2015;26:2361-2377.

37 Yang H, Wang Q, Li S: MicroRNA-218 promotes high glucose-induced apoptosis in podocytes by targeting heme oxygenase-1. Biochem Biophys Res Commun 2016;471:582-588.

-38 Yu J, Gong W, Wu Y, Li S, Cui Y, Ma Y, Zhang Y, Yang G, Huang S, Jia Z, Zhang A: mPGES-1-derived PGE2 contributes to adriamycin-induced podocyte injury. Am J Physiol Renal Physiol 2016;310:F492-498.

39 Bär H, Strelkov SV, Sjöberg G, Aebi U, Herrmann H: The biology of desmin filaments: how do mutations affect their structure, assembly, and organisation? J Struct Biol 2004;148:137-152.

40 Paulin D, Li Z: Desmin: a major intermediate filament protein essential for the structural integrity and function of muscle. Exp Cell Res 2004;301:1-7.

-41 Shah SB, Davis J, Weisleder N, Kostavassili I, McCulloch AD, Ralston E, Capetanaki Y, Lieber RL: Structural and Functional Roles of Desmin in Mouse Skeletal Muscle during Passive Deformation. Biophys J 2004;86:2993-3008.

42 Heling A, Zimmermann R, Kostin S, Maeno Y, Hein S, Devaux B, Bauer E, Klovekorn WP, Schlepper M, Schaper W, Schaper J: Increased expression of cytoskeletal, linkage, and extracellular proteins in failing human myocardium. Circ Res 2000;86:846-853.

43 Kakimoto T, Okada K, Hirohashi Y, Relator R, Kawai M, Iguchi T, Fujitaka K, Nishio M, Kato T, Fukunari A, Utsumi H: Automated image analysis of a glomerular injury marker desmin in spontaneously diabetic Torii rats treated with losartan. J Endocrinol 2014;222:43-51.

44 Floege J, Kriz W, Schulze M, Susani M, Kerjaschki D, Mooney A, Couser WG, Koch KM: Basic fibroblast growth factor augments podocyte injury and induces glomerulosclerosis in rats with experimental membranous nephropathy. J Clin Invest 1995;96:2809-2819.

45 Zhang C, Hu JJ, Xia M, Boini KM, Brimson C, Li PL: Redox signaling via lipid raft clustering in homocysteineinduced injury of podocytes. Biochim Biophys Acta 2010;1803:482-491.

-46 Eto N, Wada T, Inagi R, Takano H, Shimizu A, Kato H, Kurihara H, Kawachi H, Shankland SJ, Fujita T, Nangaku M: Podocyte protection by darbepoetin: preservation of the cytoskeleton and nephrin expression. Kidney Int 2007;72:455-463.

47 Huang F, Wang Q Ma X, Wu L, Guo F, Qin G: Valsartan inhibits amylin-induced podocyte damage. Microvasc Res 2016;106:101-109.

-48 Zuo Y, Yang HC, Potthoff SA, Najafian B, Kon V, Ma LJ, Fogo AB: Protective effects of PPARgamma agonist in acute nephrotic syndrome. Nephrol Dial Transplant 2012;27:174-181. 